\title{
土㙵飞おける低温性大腸菌群の分布
}

(昭和 50 年 6 月 30 日受理)

$\begin{array}{llll}\text { 堀江 進* } & \text { 井 } & \text { 進* } \\ \text { 神白智子* 佐 伯 和 昭* }\end{array}$

\section{Quantitative Distribution of Psychrotrophic Coliforms in Soil}

\author{
Susumu HorIE, Susumu Usui, Tomoko Kamishiro \\ and Kazuaki SAHEKI
}

(Tokyo University of Fisheries: Konan 4, Minato-ku, Tokyo)

\begin{abstract}
In winter, samples of soil were collected from mountain area along the Otake-sawa, branch of the River Tama, from Tokyo and neighbouring areas and from the plateau area in Nagano Pref. Samples of water were also collected from the Otake-sawa. Presumptive coliform counts were obtained by enumerating typical red-coloured colonies formed in the desoxycholate agar plates after $24 \mathrm{hr}$ incubation at $30^{\circ} \mathrm{C}$. Of 49 soil samples examined, 31 gave a positive presumptive test, but the presence of coliforms was confirmed in only 22 samples. The number of coliforms in the positive soils was fairly low, only 2 samples had presumptive coliform counts greater than 1,000/g. On the other hand, 7 water samples showed rather consistent coliform counts, ranging from 32 to $310 / 100 \mathrm{ml}$. Presumptive coliform counts in desoxycholate agar were fairly reliable for water samples, but not so reliable for soil samples. Among 190 coliform strains isolated from winter samples, 179 strains $(94 \%)$ were psychrotrophic and $151(79 \%)$ of these were IMViC - ++ , motility positive and gelatine liquefaction negative (Group I). Of 20 soil samples examined in autumn, 19 gave a positive presumptive test, and 16 of these showed positive completed test. Among 113 coliform isolates in autumn 77 strains $(68 \%)$ were psychrotrophic and $37(33 \%)$ of these were Group I. It was revealed that the majority of coliform strains present in soil is psychrotrophic.
\end{abstract}

(Received June 30, 1975)

温血動物の腸管に存在する大腸菌群細菌は $40^{\circ}$ 以上の 高温に発育可能で, 5 以下の低温では発育しないのが一 般である。乙かし, 冷蔵した牛乳(1) や鮮魚2)では, いわ ゆる低温性大腸菌群の増殖することが知られており，ま た著者ら ${ }^{3)}$ は東京都の山岳地の土壤, 川水, 川底の泥土 について調査を行ったところ, これらの地域では低温性 大腸菌群がきわめて容易に検出され，この種の細菌が広 く分布していることを知った。しかしその調査では, 試 料を乳糖ブイヨンに接種し，50で10日間培養し，低温菌 を選択增菌する方法を採用しているので, 試料中の大腸 菌群数ならびに全体の大腸菌群フローラに做省低温性 菌の占める割合などについては明かにしていない，本研 究ではこのような点を検討する目的で，直接デソキシコ

\footnotetext{
* 東京水産大学: 東京都港区港南 4 丁目
}

レ一ト寒天培地に接種する方法によって, 山岳地, 住宅 地域，抢よび高原地域などの土壤について調查を行い低 温性大腸菌群の分布状態を観察したので報告する。

\section{実験方法 \\ 試料の採集}

試料の採取方法は堀江ら ${ }^{3)}$ の記載に準じた．1973年12 月 8 日に東京都の多摩川支流の大岳沢の水源付近拈よび 上流に打いて土壤 9 試料を採取した。な抗この調查で は，土㙵を採取した 7 地点で溪流の水を採取し，比較観 察した．1974年1月24〜25日に東京都抢よびその周辺の 住宅地域なぞ飞扔いて土袞24試料を, 長野県の高原地域 に打いて土袞16試料を採集した。 以上の冬期の試料のほ か，秋期の試料として1974年 9 月 24 25日に長野県の高 原地域で土壤 20 試料を採集し, 比較検討した。 


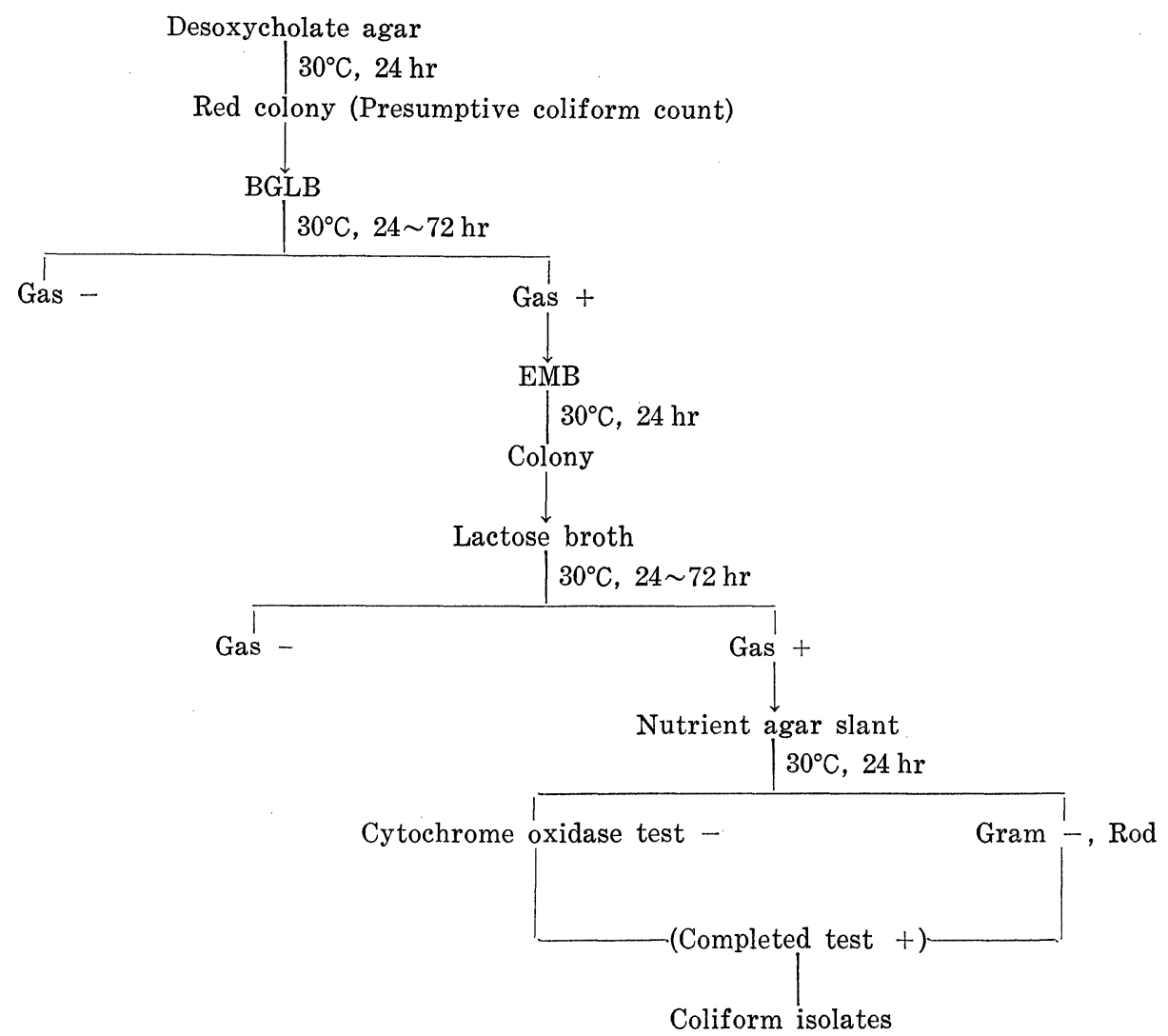

Scheme 1. Scheme for the determination of presumptive coliform counts and completed test of the isolates

\section{大腸菌群の測定と菌株の分離}

土壤の試料は，その $10 \mathrm{~g}$ をとり，リン酸緩衝生理食 塩水 $100 \mathrm{ml}$ に入れ，ときどきサーモミキサーでかくは んしながら 30 分間処理したものを試料原液とし，原液招 いび10倍希釈液の $1 \mathrm{ml}$ をそれぞれ 5 枚のデソキシコレ 一下寒天培地に混和し，冷却凝固した後さらに同培地 $3 \sim 4 \mathrm{ml}$ を加穴薄層をかぶせた，一方，水の試料の場合 には，採取当日にその 100 拈よび $10 \mathrm{ml}$ をミリポアフィ ルター (Type HA pore size $0.45 \mu$ ) でろ過し，これを デソキシコレート寒天平板培地の上にのせ，その上にさ らに同培地 $3 \sim 4 \mathrm{ml}$ を流し込んで薄層をかぶせた。接 種したデソキシコレート寒天培地を $30^{\circ}$ で 24 時間培養し た後, 定型的赤色集落を数兄, 推定大腸菌群数とした. 各試料の定型的集落の中から冬期の試料では 20 個または それ以下，秋期の試料では15個またはそれ以下から釣菌 し, Scheme 1 の手順により完全試験を行った.

\section{生物学的性状検查法}

IMViC 型, 運動性, ゼラチン液化, 硝酸塩還元, チ トクロムオキシダーゼなどの試験ならびに各種温度にお ける発育試験は堀江ら ${ }^{3)}$ の記載によった。

\section{実 験 結 果}

\section{分離菌株の群別}

冬期に実施した大岳沢の水, 土壤, 東京都抢よびその 周辺地域の土壤, 長野県の高原地域の土壤の試料につい て, デソキシコレート寒天培地により大腸菌群数を測定 し,さらに分離した大腸菌群 190 株について, IMViC

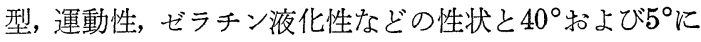
抢ける発育試験の結果とを組み合わせて群別した。 また 秋期に行った長野県高原地域の土埪についても同様に行 い，分離した大腸菌群 113 株を群別した，分離菌株の群 別の結果を冬期と秋期に分けて Table 1 に示した.

\section{大腸菌群の測定結果}

冬期に実施した大岳沢の溪流水および土壤の大腸菌群 測定成績を Table 2 と示した.

水温は $5^{\circ}$ をたそれ以下であった。水の 7 試料のすべ てから大腸菌群が検出され， $100 \mathrm{ml}$ 中の推定大腸菌群 数は 32 から 310 範团であった。 デソキシコレート寒天 培地の集落について完全試験を行ったところ，汪とんど すべてが大腸菌群に同定された．すなわちこのような渓 流水の場合のデソキシコレート寒天培地による大腸菌群 
Table 1. Coliform Distribution by IMViC Types, Motility, Gelatine Liquefaction, and Growth Temperature Test

\begin{tabular}{|c|c|c|c|c|c|c|c|c|c|c|c|c|c|c|c|}
\hline & & & & & & & \multicolumn{4}{|c|}{ Isolates in winter } & \multicolumn{5}{|c|}{ Isolates in autumn } \\
\hline \multicolumn{7}{|c|}{ Grouping by growth temperature test } & A & $\mathrm{B} \mathrm{C}$ & $\mathrm{D}$ & $\mathrm{E}$ & $\mathrm{A}$ & $\mathrm{B}$ & $\mathrm{C}$ & $\mathrm{D}$ & $\mathrm{E}$ \\
\hline \multirow{3}{*}{ Growth at } & \multicolumn{6}{|c|}{$40^{\circ} \mathrm{C}$} & - & -+ & + & + & - & - & + & + & + \\
\hline & \multirow{2}{*}{\multicolumn{3}{|c|}{$5^{\circ} \mathrm{C}$}} & \multicolumn{3}{|c|}{$7 \sim 10$ days } & & + & + & - & & + & & + & - \\
\hline & & & & \multicolumn{3}{|c|}{6 days } & + & $-\quad+$ & - & - & + & - & + & - & - \\
\hline Group & I & M & $\mathrm{V}$ & $\mathrm{C}$ & Mo & $\mathrm{G}$ & & & & & & & & & \\
\hline I & - & - & + & + & + & - & $151^{*}$ & & & 2 & 25 & 1 & 11 & & 2 \\
\hline II & - & - & + & + & + & + & 6 & & & & 1 & & 4 & & \\
\hline III & - & - & + & + & - & - & & 4 & & & 1 & & 5 & 2 & 1 \\
\hline IV & - & + & - & + & + & - & 2 & & 3 & 2 & 1 & & 7 & 3 & 2 \\
\hline $\mathrm{V}$ & - & + & - & + & + & + & & & & & & & & & 1 \\
\hline VI & - & + & - & + & - & - & & & & 1 & & & & & \\
\hline VII & - & - & - & + & + & - & 2 & & & & & & & & \\
\hline VIII & - & - & - & + & + & + & 1 & & & & & & & & \\
\hline IX & - & + & + & + & + & - & & & & & 1 & & 1 & & \\
\hline $\mathrm{x}$ & - & + & + & + & + & + & 1 & & & 1 & & & & & \\
\hline XI & - & + & + & - & + & - & 1 & & & & 1 & & & & \\
\hline XII & + & - & + & + & - & - & & 1 & & 1 & & & 1 & 1 & \\
\hline XIII & + & + & - & + & + & - & & & & & & & 1 & & 12 \\
\hline XIV & + & + & - & + & - & - & & & & & & & & & 2 \\
\hline $\mathrm{XV}$ & + & + & - & - & + & - & & & & 1 & & & & 6 & 12 \\
\hline XVI & + & + & - & - & - & - & & & & 3 & & & & & 3 \\
\hline XVII & + & - & - & - & + & - & & & & & & & & & 1 \\
\hline XVIII & + & - & - & + & + & - & 1 & & & & & & & & \\
\hline XIX & + & + & + & + & - & - & & & 6 & & & & 1 & 3 & \\
\hline \multirow{2}{*}{\multicolumn{7}{|c|}{ Total }} & 165 & 5 & 9 & 11 & 30 & 1 & 31 & 15 & 36 \\
\hline & & & & & & & \multicolumn{4}{|c|}{190} & & & 113 & & \\
\hline
\end{tabular}

* Figure represents number of strains isolated.

の測定においては，誤りの陽性がきわめて少なく正確性 の高いことが示唆された。一方，土壤の場合には，9試 料中 5 試料のみに大腸菌群が検出され, 推定大腸菌群数 は最高が $710 / g$ であった。 陽性の 5 試料中 3 試料では完 全試験の結果高い陽性率を示したが，2 試料では陽性率 が低かった。

分離菌株の群別をしたところ，水の大腸菌群フローラ のほとんどすべてが IA 群すなわち IMViC 型がーーー +で，運動性を有し，ゼラチン液化性を欠き，50で速や かに発育するが $40^{\circ}$ で発育しないものである，土壌の試 料でもやはり IA 群が多かった.

冬期に行った東京都执よびその周辺地域の成績を Table 3 に示した.
24試料中，推定大腸菌群測定值が得られたのは14試料 であったが，完全試験の結果，大腸菌群の存在が確認さ れたのはわずか 6 試料で，乙かも完全試験における陽性 率は 2 試料を除いて非常に低かった。分離菌株の大部分 は50で発育し， $40^{\circ}$ で発育しない種類であった。

冬期の長野県高原地域に打ける成績を Table 4 に示 した.

16 試料中，12試料に沶いて推定大腸菌群測定值が得ら れ，そのらち11試料で完全試験の結果大腸菌群が検出さ れた. 推定大腸菌群数の最高値は $2250 / \mathrm{g}$ であった。分 離菌株を群別したところ, IA 群が大部分を占めてお り，典型的中温細菌といえるものは検出されなかった。 秋期の長野県高原地域の土壌についての成績を Table 
Table 2. Enumeration of Coliforms in Waters and Soils Collected along the Otake-sawa in Winter and Grouping of the Isolates

\begin{tabular}{|c|c|c|c|c|c|c|c|c|c|c|c|}
\hline \multicolumn{7}{|c|}{ Water } & \multicolumn{5}{|c|}{ Soil } \\
\hline \multirow{2}{*}{ 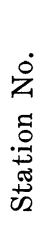 } & \multirow{2}{*}{ 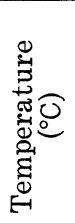 } & \multirow{2}{*}{ 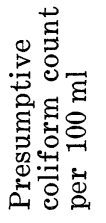 } & \multicolumn{2}{|c|}{$\begin{array}{c}\text { Completed } \\
\text { test }\end{array}$} & \multicolumn{2}{|c|}{$\begin{array}{l}\text { Grouping } \\
\text { test }\end{array}$} & \multirow{2}{*}{ 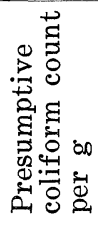 } & \multicolumn{2}{|c|}{$\begin{array}{c}\text { Completed } \\
\text { test }\end{array}$} & \multicolumn{2}{|c|}{ Grouping test } \\
\hline & & & $\begin{array}{l}\text { No. of } \\
\text { colonies } \\
\text { tested }\end{array}$ & $\begin{array}{l}\text { No. of } \\
\text { colonies } \\
\text { positive }\end{array}$ & $\begin{array}{l}\text { No. of } \\
\text { strains } \\
\text { tested }\end{array}$ & $\begin{array}{l}\text { No. of } \\
\text { strains } \\
\text { of each } \\
\text { group }\end{array}$ & & $\begin{array}{l}\text { No. of } \\
\text { colonies } \\
\text { tested }\end{array}$ & $\begin{array}{l}\text { No. of } \\
\text { colonies } \\
\text { positive }\end{array}$ & $\begin{array}{l}\text { No. of } \\
\text { strains } \\
\text { tested }\end{array}$ & $\begin{array}{l}\text { No. of strains } \\
\text { of each group }\end{array}$ \\
\hline 1 & & & & & & & 0 & & & & \\
\hline 2 & & & & & & & 710 & 20 & 20 & 10 & IA -10 \\
\hline 3 & 5.0 & 32 & 20 & 20 & 10 & IA-10 & 17 & 9 & 1 & 1 & XIIB-1 \\
\hline 4 & 5.0 & 310 & 20 & 20 & 9 & IA-9 & 180 & 20 & 18 & 10 & IA-7, IIIB-3 \\
\hline 5 & 3.2 & 88 & 20 & 16 & 10 & IA-10 & 0 & & & & \\
\hline 6 & 3.0 & 68 & 20 & 17 & 10 & IA-10 & 0 & & & & \\
\hline 7 & 2.5 & 88 & 20 & 19 & 10 & IA -10 & 0 & & & & \\
\hline 8 & 2.8 & 290 & 20 & 19 & 10 & $\begin{array}{l}\text { IA-9 } \\
\text { IIIB-1 }\end{array}$ & 5 & 3 & 1 & 1 & $\mathrm{IA}-1$ \\
\hline 9 & 4.0 & 56 & 20 & 19 & 10 & $\begin{array}{l}\text { IA-8 } \\
\text { VIIA-1 } \\
\text { VIIIA-1 }\end{array}$ & 55 & 20 & 19 & 10 & $\begin{array}{l}\text { IA-1, XVE-1 } \\
\text { XVIE-3,XIIE-1 } \\
\text { XIXD-4 }\end{array}$ \\
\hline
\end{tabular}

5 に示した.

推定大腸菌群数も完全試験に就ける陽性率も試料によ りまらまちであったが，20試料中16試料で大腸菌群が検 出された. Table 1 に示したよらに分離菌113株中, IA 群は25株で冬期の場合に比べるとはるかに少なかった。 しかし，50で発育する菌株は77株を占めており，典型的 中温細菌といえるものは 36 株であった。

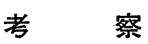

デソキシコレート寒天培地による大腸菌群測定は渓流 水試料の場合に高い選択性がみられ，Table 2 に拈ける 推定大腸菌群数は信頼性の高い数值である. 冬期で水温 の低い関係から分離菌株が低温発育性を有する点は推測 されたことではあるが， ほとんどすべての菌株が IA 群 であるといら目立った現象がみられた。冬期の土壤のデ ソキシュレート寒天培地による推定大腸菌群の測定值の 正確性は試料によりかなりまちまちであったが，完全試 験の成績と組み合わせることにより大腸菌群の数的分布 状態の概況を知ることは可能である．冬期の長野県高原 地方は特に気温が低く, 当然凍結しているので Warseck $ら^{4)}$, 矢野 $5^{5)}$, 堀江 $5^{6)}$ の述べるように大腸菌群は凍結 による損傷を受け，生残菌の中にもデソキシコレート寒 天培地に打汀る集落形成能を失っているものが多いこと を考えに入れておかねばならない.土壤中の大腸菌群数 については Taylor ${ }^{7)}$, Randall ${ }^{8)}$ らの報告にもあるが, 概して菌数はかなり小さいとされている，本調査でも検 出されない試料がかなり多く，また陽性の試料において も推定大腸菌群数が $1000 / g$ を超えるものはまれであっ
た。冬期の土壤試料に护ける大腸菌群の群別をみると概 して IA 群が多数を占めている点が目立っている. IMViC - - + + 型の中でもゼラチン液化菌あるいは非 運動性の種類はきわめて少数であることが観察された。

秋期の高原の土壌の場合には冬期に比べ，はるかに菌 群に分散が認められる。すなわら 113 株中 IA 群は25株 にすぎず，冬期には非常に少なかったインドール陽性の 菌群もかなり多く見いだされた。このような成績から IA 群は他の大腸菌群細菌に比べて寒冷に対し 抵抗性が 高いことが推察される.

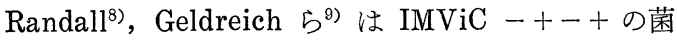
型が土壤においては特に重要な位置にあると述べてい る.しかし，本調査ではそのような現象は認められず， ーー+十の菌型が数的に最も重要な部分を占めた.この ような成績の違いは一つには測定と分離に打㥉地の 種類や培養条件によるものであるう。

冬期の分離大腸菌群 190 株中， $40^{\circ}$ で発育不能のものは 170 株に及んだ。また秋期の分離菌113株中では 31 株が含 まれている。

Burman $^{10)}$ は糞便に存在する大腸菌群は一般に $42^{\circ} て ゙$ 発育可能であるが，河水，下水などには $42^{\circ}$ で発育でき ない大腸菌群細菌がかなり多いと述べている。このよう な污染された河水あるいは下水中の大腸菌群の中で大き な部分を占める低温性菌株が自然界の土壌ならびに溪流 水などに由来する可能性は，本研究の結果からも十分考 えられるところである。 
Table 3. Enumeration of Coliforms in Soils Collected in Tokyo and Neighbouring Areas in Winter and Grouping of the Isolates

\begin{tabular}{|c|c|c|c|c|c|c|}
\hline \multirow{2}{*}{\multicolumn{2}{|c|}{ Station }} & \multirow{3}{*}{$\begin{array}{l}\text { Presumptive } \\
\text { coliform } \\
\text { count per } \mathrm{g}\end{array}$} & \multicolumn{2}{|c|}{ Completed test } & \multicolumn{2}{|r|}{ Grouping test } \\
\hline & & & \multirow{2}{*}{$\begin{array}{c}\text { No. of } \\
\text { colonies } \\
\text { tested }\end{array}$} & \multirow{2}{*}{$\begin{array}{l}\text { No. of } \\
\text { colonies } \\
\text { positive }\end{array}$} & \multirow{2}{*}{$\begin{array}{l}\text { No. of } \\
\text { strains } \\
\text { tested }\end{array}$} & \multirow{2}{*}{$\begin{array}{l}\text { No. of strains } \\
\text { of each group }\end{array}$} \\
\hline No. & Location & & & & & \\
\hline $\begin{array}{l}1 \\
2 \\
3 \\
4 \\
5\end{array}$ & $\begin{array}{l}\text { Wood, Yokosuka } \\
\text { Wood, Yokosuka } \\
\text { Roadside, Yokosuka } \\
\text { Wood, Miura } \\
\text { Wood, Yokosuka }\end{array}$ & $\begin{array}{r}<10 \\
<10 \\
74 \\
4 \\
4\end{array}$ & $\begin{array}{r}20 \\
2 \\
2\end{array}$ & $\begin{array}{l}0 \\
1 \\
0\end{array}$ & 1 & XVIIIA-1 \\
\hline $\begin{array}{r}6 \\
7 \\
8 \\
9 \\
10\end{array}$ & $\begin{array}{l}\text { Wood, Yokosuka } \\
\text { Wood, Yokosuka } \\
\text { Grassplot, Yokosuka } \\
\text { Garden, Ota-ku, Tokyo } \\
\text { Garden, Ota-ku, Tokyo }\end{array}$ & $\begin{array}{r}6 \\
56 \\
40 \\
4 \\
<10\end{array}$ & $\begin{array}{r}3 \\
10 \\
9 \\
2\end{array}$ & $\begin{array}{l}0 \\
0 \\
1 \\
0\end{array}$ & 1 & IVA-1 \\
\hline $\begin{array}{l}11 \\
12 \\
13 \\
14 \\
15\end{array}$ & $\begin{array}{l}\text { Garden, Ota-ku, Tokyo } \\
\text { Garden, Ota-ku, Tokyo } \\
\text { Wood, Yokohama } \\
\text { Wood, Yokohama } \\
\text { Grassplot, Abiko }\end{array}$ & $\begin{array}{r}14 \\
<10 \\
196 \\
<10 \\
92\end{array}$ & $\begin{array}{l}17 \\
20\end{array}$ & $\begin{array}{l}16 \\
16\end{array}$ & $\begin{array}{l}10 \\
10\end{array}$ & $\begin{array}{l}\text { IA-9, IVE-1 } \\
\text { IA-7, IIA-1, IE-1, XA-1 }\end{array}$ \\
\hline $\begin{array}{l}16 \\
17 \\
18 \\
19 \\
20\end{array}$ & $\begin{array}{l}\text { Wood, Abiko } \\
\text { Wood, Hino } \\
\text { Wood, Hino } \\
\text { Wood, Fujisawa } \\
\text { Wood, Fujisawa }\end{array}$ & $\begin{array}{r}<10 \\
<10 \\
8 \\
58 \\
136\end{array}$ & $\begin{array}{r}4 \\
14 \\
12\end{array}$ & $\begin{array}{l}0 \\
1 \\
5\end{array}$ & $\begin{array}{l}1 \\
5\end{array}$ & $\begin{array}{l}\text { IVE-1 } \\
\text { IE-1, VIE-1, XE-1, XIXD-2 }\end{array}$ \\
\hline $\begin{array}{l}21 \\
22 \\
23 \\
24\end{array}$ & $\begin{array}{l}\text { Garden, Meguro-ku, Tokyo } \\
\text { Roadside, Meguro-ku, Tokyo } \\
\text { Wood, Zushi } \\
\text { Wood, Zushi }\end{array}$ & $\begin{array}{l}<10 \\
<10 \\
<10 \\
10\end{array}$ & 5 & 0 & & \\
\hline
\end{tabular}

Table 4. Enumeration of Coliforms in Soils Collected in the Plateau Area of Nagano Pref. in Winter and Grouping of the Isolates

\begin{tabular}{|c|c|c|c|c|c|c|}
\hline \multicolumn{2}{|r|}{ Station } & \multirow{2}{*}{$\begin{array}{l}\text { Presumptive } \\
\text { coliform count } \\
\text { per } g\end{array}$} & \multicolumn{2}{|c|}{ Completed test } & \multicolumn{2}{|c|}{ Grouping test } \\
\hline No. & Location & & $\begin{array}{l}\text { No. of } \\
\text { colonies } \\
\text { tested }\end{array}$ & $\begin{array}{l}\text { No. of } \\
\text { colonies } \\
\text { positive }\end{array}$ & $\begin{array}{l}\text { No. of } \\
\text { strains } \\
\text { tested }\end{array}$ & $\begin{array}{l}\text { No. of strains } \\
\text { of each group }\end{array}$ \\
\hline 1 & Wood, Karuizawa & $<10$ & & & & \\
\hline 2 & Wood, Karuizawa & 18 & 6 & 1 & 1 & IA -1 \\
\hline 3 & Wood, Minenochaya & 14 & 5 & 1 & 1 & IA-1 \\
\hline 4 & Wood, Minenochaya & $<10$ & & & & \\
\hline 5 & Wood, Minenochaya & $<10$ & & & & \\
\hline 6 & Wood, Minenochaya & 2,250 & 20 & 20 & 10 & IA -10 \\
\hline 7 & Wood, Komoro & 28 & 10 & 6 & 6 & IA-6 \\
\hline 8 & Wood, Komoro & 54 & 13 & 0 & & \\
\hline 9 & Wood, Lake Matsubara & 70 & 17 & 13 & 10 & IA -6, IIA-4 \\
\hline 10 & Wood, Lake Matsubara & 4 & 2 & 1 & 1 & IA-1 \\
\hline 11 & Wood, Koumi & 36 & 15 & 8 & 8 & IA-4, IIA-1, IVD-3 \\
\hline 12 & Wood, Koumi & 1,480 & 20 & 16 & 10 & IA-9, VIIA-1 \\
\hline 13 & Wood, Usuda & 78 & 20 & 18 & 9 & IA -9 \\
\hline 14 & Wood, Usuda & 14 & 5 & 1 & 1 & IA-1 \\
\hline 15 & Garden, Shionada & $<10$ & & & & \\
\hline 16 & Riverside bank, Shionada & 46 & 11 & 4 & 4 & IA-2, IVA-1, XIA-1 \\
\hline
\end{tabular}


Table 5. Enumeration of Coliforms in Soils Collected in the Plateau Area of Nagano Pref. in Autumn and Grouping of the Isolates

\begin{tabular}{|c|c|c|c|c|c|}
\hline \multicolumn{2}{|r|}{ Station } & \multirow{2}{*}{ 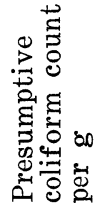 } & \multicolumn{2}{|c|}{ Completed test } & \multirow{2}{*}{ Grouping } \\
\hline No. & Location & & $\begin{array}{l}\text { No. of } \\
\text { colonies } \\
\text { tested }\end{array}$ & $\begin{array}{l}\text { No. of } \\
\text { colonis } \\
\text { positive }\end{array}$ & \\
\hline 1 & Wood, Komoro & $<10$ & & & \\
\hline 2 & Wood, Komoro & 5,700 & 15 & 1 & IC-1 \\
\hline 3 & Wood, Miyota & 1,000 & 15 & 0 & \\
\hline 4 & Wood, Miyota & 350 & 7 & 0 & \\
\hline 5 & Wood, Karuizawa & 122 & 15 & 9 & IA-2, IC-1, IIIA-1, IVC-5 \\
\hline 6 & Wood, Karuizawa & 26 & 11 & 0 & \\
\hline 7 & Wood, Minenochaya & 1,860 & 15 & 8 & IA-6, IVC-2 \\
\hline 8 & Wood, Minenochaya & 550 & 15 & 10 & IA-4, IIC-1, IIIC-4, XIID-1 \\
\hline 9 & Wood, Minenochaya & 1,120 & 15 & 11 & IA-3, IB-1, IIA-1, IIC-2, XIA-1, XVD-3 \\
\hline 10 & Wood, Minenochaya & 6,150 & 15 & 1 & IIC-1 \\
\hline 11 & Wood, Saku & 590 & 15 & 12 & IIIE-1, XVD-3, XVE-5, XVIE-3 \\
\hline 12 & Wood, Saku & 146 & 15 & 3 & IE-1, XIIC-1, XIIIE-1 \\
\hline 13 & Riverside bank, Shionada & 10 & 4 & 2 & XIIIC-1, XIXC-1 \\
\hline 14 & Riverside bank, Shionada & 72 & 15 & 4 & IIIC-1, XIIIE-1, XIXD-2 \\
\hline 15 & Wood, Kasatori-toge & 1,300 & 15 & 8 & IA-4, IVE-1, XIIIE-2, XIXD-1 \\
\hline 16 & Wood, Kasatori-toge & 370 & 15 & 14 & IA-2, IC-9, IE-1, IXC-1, XVIIE-1 \\
\hline 17 & Wood, Daimon & 68 & 15 & 5 & IA-1, IVD-2, XIVE-2 \\
\hline 18 & Wood, Daimon & 232 & 15 & 14 & IA-1, XIIIE-6, XVE-7 \\
\hline 19 & Wood, Maruko & 5,850 & 15 & 5 & IA-2, IVA-1, IVD-1, IXA-1 \\
\hline 20 & Wood, Maruko & 650 & 15 & 6 & IIID-2, IVE-1, VE-1, XIIIE-2 \\
\hline
\end{tabular}

\section{要約}

自然界の土壤抢よび水に打ける大腸菌群をデソキシュ レート寒天培地に $30^{\circ}$ で培養する方法で測定し，かつ大 腸菌群フローラを形成する菌株を IMViC 型, 運動性, ゼラチン液化性, $40^{\circ}$ 执よび $5^{\circ}$ に打ける発育能などの組 み合わせにより分類した。

冬期に東京都大岳沢の水, 土壤, 東京都とその周辺地 域および長野県高原地域における土壌について調査した ところ, 推定大腸菌群数は溪流水で $32 \sim 310 / 100 \mathrm{ml}$, 土 壌では陰性の試料がかなり多く，陽性の試料でも 1000/ $\mathrm{g}$ を超えるものはまれであった. 冬期の分離大腸菌群 190 株中，5に発育可能の低温性菌は 179 株もあり，その 中151株は IMViC 型-ー++, 運動性を有し, ゼラチ ソ非液化性のもの（I 群）であった。 また秋期に長野県 高原地域の土㙵を調査したところ, 分離大腸菌群 113 株 中， $5^{\circ}$ で発育するものは77株に達し，その中，I群に属 するものは37株であった. 自然界の土謮などに分布する 大腸菌群フローラの大部分が低温性菌株によって占めら れていることが示唆された。

\section{文献}

1) Panes, J. J., Thomas, S. B.: J. Appl. Bact., 31, 420 (1968).

2) 佐伯和昭, 堀江 進, 慶野一夫：食衛誌. 12, 95 (1971).

3) 堀江 進，荒木敏明，佐伯和昭：同上. 13, 405 (1972).

4) Warseck, M., Ray, B., Speck, M. L.: Appl. Microbiol., 26, 919 (1973).

5) 矢野信礼, 森地敏樹: 食衛誌. 12, 408 (1971).

6) 堀江 進, 山形 誠, 井上広志, 和泉 力: 同 上. 15, 110 (1974).

7) Taylor, C. B.: J. Hyg., Camb., 49, 162 (1951).

8) Randall, J.S.: ibid., 54, 365 (1956).

9) Geldreich, E. E., Huff, C. B., Bordner, R. H., Kabler, P. W., Clark, H. F.: J. appl. Bact., 25, 87 (1962).

10) Burman, N.P.: ibid., 24, 368 (1961). 